\title{
Harnessing Omics Approaches on Advanced Preclinical Models to Discovery Novel Therapeutic Targets for the Treatment of Metastatic Colorectal Cancer
}

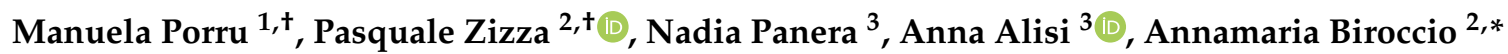 \\ and Carlo Leonetti ${ }^{1, *(\mathbb{D})}$ \\ 1 UOSD SAFU, Department of Research, Advanced Diagnostic, and Technological Innovation, \\ IRCSS-Regina Elena National Cancer Institute, 00144 Rome, Italy; manuela.porru@ifo.gov.it \\ 2 UOSD Oncogenomic and Epigenetic Unit, Department of Research, Advanced Diagnostic, and Technological \\ Innovation, IRCSS-Regina Elena National Cancer Institute, 00144 Rome, Italy; pasquale.zizza@ifo.gov.it \\ 3 Research Unit of Molecular Genetics of Complex Phenotypes, Bambino Gesù Children's Hospital, IRCCS, \\ 00165 Rome, Italy; nadia.panera@opbg.net (N.P.); anna.alisi@opbg.net (A.A.) \\ * Correspondence: annamaria.biroccio@ifo.gov.it (A.B.); carlo.leonetti@ifo.gov.it (C.L.) \\ + Equally contributors.
}

Received: 1 June 2020; Accepted: 6 July 2020; Published: 8 July 2020

\begin{abstract}
Metastatic colorectal cancer (mCRC) remains challenging because of the emergence of resistance mechanisms to anti-epidermal growth factor receptor (EGFR) therapeutics, so more effective strategies to improve the patients' outcome are needed. During the last decade, the application of a multi-omics approach has contributed to a deeper understanding of the complex molecular landscape of human CRC, identifying a plethora of drug targets for precision medicine. Target validation relies on the use of experimental models that would retain the molecular and clinical features of human colorectal cancer, thus mirroring the clinical characteristics of patients. In particular, organoids and patient-derived-xenografts (PDXs), as well as genetically engineered mouse models (GEMMs) and patient-derived orthotopic xenografts (PDOXs), should be considered for translational purposes. Overall, omics and advanced mouse models of cancer represent a portfolio of sophisticated biological tools that, if optimized for use in concert with accurate data analysis, could accelerate the anticancer discovery process and provide new weapons against cancer. In this review, we highlight success reached following the integration of omics and experimental models; moreover, results produced by our group in the field of $\mathrm{mCRC}$ are also presented.
\end{abstract}

Keywords: colon cancer; anti-EGF; new therapies; organoids; PDXs; orthotopic tumors; GEMM; omics technologies

\section{Introduction}

Worldwide, colorectal cancer (CRC) is the third most common cancer with more than 1.8 million cases accounting for about $10 \%$ of all annually new cancer diagnoses and the third cause of cancer-related deaths with a mortality rate of 880,000 people [1]. Considerable progress in the prognosis of metastatic CRC (mCRC) was made from the end of the last century when the overall survival was about 12 months to the current 30 months. Several factors have contributed to the increase of the mCRC patients' outcomes, including the introduction of large-scale screening programs, the surgical resection of liver metastases, and the optimization of systemic chemotherapy (FOLFOX, FOLFIRI, or FOLFOXIRI). Moreover, the introduction of biological therapies based on the use of monoclonal antibodies (mAbs) 
against either epidermal growth factor receptor (EGFR)—cetuximab and panitumumab—or vascular endothelial growth factor-A (VEGF-A)—bevacizumab—significantly improved patients' survival [2].

Notwithstanding this advancement, the treatment of $\mathrm{mCRC}$ represents a great challenge for oncologists, as the five-year survival rate is less than $15 \%$ [1]; thus, the identification of more effective therapeutic strategies is of paramount importance. From this point of view, the use of complex omics technologies is particularly relevant to deeply investigate the molecular landscape of mCRC. Moreover, the integration of omics data with the functional validation of druggable targets in experimental preclinical models able to recapitulate heterogeneity of mCRC could be an excellent approach for the discovery and development of novel therapeutics.

In this review, we give an overview the state of art and discuss recent progress in this field of research. Moreover, to make the design and analysis of in vivo experiments more powerful for clinical application, the application of the Response Evaluation Criteria In Solid Tumors (RECIST) of mice is also discussed.

\section{Validated Biomarkers of Response to Anti-EGFR mAbs Treatment}

A key piece of data in the treatment of mCRC was represented by the approval in 2004 of cetuximab, a monoclonal antibody specific for the extracellular ligand-binding domain of EGFR. This receptor is over-expressed in $60-80 \%$ of tumors and has a pivotal role in the growth and progression of $\mathrm{mCRC}$, and, when it is over-expressed, is associated with poor prognosis [3]. Randomized clinical trials, that followed promising pre-clinical studies, demonstrated that cetuximab was effective in combination with irinotecan in over-expressing EGFR mCRC patients who previously did not respond to single therapy with irinotecan [4]. Importantly, subsequent studies showed that the efficacy of cetuximab and panitumumab (approved in 2006) was limited to the patients with $R A S$ wild-type (WT) tumors, as mutations in EGFR signaling may induce receptor-independent pathways that render the tumors unresponsive to anti-EGFR-based therapy. In fact, activating mutations in hot spot regions of exons 2, 3 , and 4 of the KRAS or of NRAS genes, reported in more than $50 \%$ of mCRC cases, were responsible for the primary resistance to anti-EGFR therapy and represented the major exclusion criteria for treatment of patients with these drugs [5].

Only $30-40 \%$ of mCRC patients unresponsive to anti-EGFR treatment have been found to be positive for RAS mutations [6]. In addition, it was reported that EGFR signaling activation affected not only the RAS/RAF/MAPK+ pathway but also the PTEN-PI3K-Akt cascade [7]. All of these observations have prompted investigators to analyze the involvement in $\mathrm{mCRC}$ resistance to anti-EGFR $\mathrm{mAbs}$ of other genes of the RAS/RAF/MAPK and PI3K/PTEN/Akt pathways. In particular, a mutation in the $B R A F$ gene, which encodes a downstream effector of KRAS, resulting in the constitutive activation of the MAPK pathway, was found in about $6 \%$ of mCRC patients with no overlap with the RAS mutation [8]. In particular, a retrospective study by Di Colantonio [9], performed in 113 tumor samples from $\mathrm{mCRC}$ patients treated with cetuximab or panitumumab, demonstrated that the presence of the BRAF V600E mutation impaired the response to anti-EGFR treatment. The role of this mutation in interfering with the efficacy of anti-EGFR was also confirmed in tumor cells naturally or experimentally bearing the BRAFV600E mutation. Further retrospective and meta-analyses studies have more recently confirmed the prognostic value of $B R A F$ as a biomarker for predicting the efficacy of anti-EGFR mAbs therapy $[2,10]$.

On this basis, according to international guilines, the analysis of alterations in the RAS and BRAF genes is mandatory for selecting patients eligible for anti-EGRF mAbs treatment, thus leading to clinical and economic advantages.

\section{Emerging Biomarkers of Response to Anti-EGFR mAbs Treatment}

Other than mutational status of $R A S$ and $B R A F$, further biomarkers are emerging as possible responsible for the innate resistance to anti-EGFR $m A b s$, such as alterations in the parallel or downstream pathways of the EGFR signaling. 
HER2: The human EGFR-2 (HER2), an oncogene that encodes for a transmembrane glycoprotein receptor, functions as an intracellular tyrosine kinase and is involved in the activation of two signal transduction pathways (RAS-RAF-ERK and PI3K-PTEN-AKT). HER2 gene amplification was reported in $7 \%$ of patients with CRC [11], and this was associated with the resistance of the tumor to anti-EGFR therapy [12]. The authors used an approach that was, at that time, very innovative and was based on a cohort of $85 \mathrm{mCRC}$ genetically characterized patient-derived xenografts (PDXs) that recapitulate the molecular heterogeneity observed in clinical studies. In particular, the authors observed that PDXs harboring wild-type KRAS/NRAS/BRAF/PIK3CA genes but HER2 amplification were resistant to cetuximab. However, the administration of trastuzumab (an anti-HER2 $\mathrm{mAb}$ ) or lapatinib (a tyrosine kinase inhibitor effective against HER2) was able to inhibit tumor growth, demonstrating the role of HER-2 in primary resistance to anti-EGFR mAbs. These observations were subsequently confirmed both in CRC cells transfected with activating HER2 gene mutations and in mice-bearing HER2-mutated xenografts [13]. Later, further clinical studies confirmed the role of HER2 amplification in predicting response to anti-EGFR treatment. In particular, a retrospective study demonstrated that in $R A S / B R A F$ WT mCRC patients without HER2 amplification, the anti-EFGR treatment produced a significantly longer progression-free survival (PFS) than patients harboring HER2 amplification [14]. While these observations need to be confirmed in larger studies, the study suggested the role of HER2 amplification as a negative biomarker of response just like $R A S$ mutations and that the assessment of HER2 amplification, in addition to HER2 mutations, could be critical to therapeutic decisional tree.

c-MET: This protein, also known as tyrosine protein kinase MET or mesenchymal-epithelial transition factor, has a key role in initiating a range of signals that regulate various cellular functions and has been suggested to be involved with the growth, survival, and progression of CRC [15]. $c-M E T$ overexpression and/or amplification has been associated not only with poor outcomes, especially in patients at advanced stage [16], but also as a predictor of resistance to anti-EGFR-mAbs. To this purpose, Bardelli's group reported that KRAS WT patients, who did not respond to cetuximab or panitumumab, were characterized by MET amplification [17]. Based on these observations, they deeply investigated the relationship between MET amplification and resistance to anti-EGFR therapy [12]. The authors confirmed that mCRC PDXs with KRAS, BRAF, NRAS, or PIK3CA mutated or with the amplification of HER2 were resistant to cetuximab treatment. At the same time, the study highlighted that the presence of these alterations did not correspond with the number of PDXs that were resistant to cetuximab. Interestingly, they observed that in the population of PDXs WT for KRAS, BRAF, NRAS, $P I K 3 C A$, and HER2, a significant fraction of the tumors resistant to cetuximab were characterized by MET amplification. These observations were confirmed in cell lines and in xenografts WT for KRAS, $B R A F, N R A S, P I K 3 C A$, and HER2, with the ectopic overexpression of MET. Importantly, the use of a specific anti-MET inhibitor restored the sensitivity of these cells, thus corroborating the role of MET in driving resistance to anti-EGFR mAbs [17].

PTEN: The phosphatase and tensin homologue deleted on chromosome ten (PTEN) is a tumor suppressor gene that acts through the negative regulation of the PI3K/Akt pathway, another pathway that is associated to EGFR signaling. PTEN loss, by germinal or somatic mutations, has been observed in $30 \%$ of CRC [18], but its role in predicting the clinical benefit to anti-EGFR treatment has not been fully ascertained. In fact, Frattini and colleagues [19] reported that when patients had intact PTEN, most of them responded to cetuximab-based chemotherapy, while no benefits were observed in patients with PTEN loss, notwithstanding the EGFR gene amplification and the presence of KRAS WT. In contrast, Karapetis and co-workers [20] reported that there was a no positive correlation between loss of PTEN and lack of response to anti-EGFR mAbs. In fact, it was observed in this study that patients with PTEN protein expression was not predictive of benefit from treatment, both in the whole study population and in the KRAS WT subset.

PIK3CA: The role of alterations in the p110 $\alpha$ subunit of PI3K gene $(P I K 3 C A)$ is still under investigation. PIK3CA mutations are reported in exons 9 and 20 and occur in $30 \%$ of CRC cases [21]; the activation of $\mathrm{p} 110 \alpha$ leads to the production of phosphatidylinositol 3,4,5-triphosphate (PIP3), which, 
in turn, is a substrate of PTEN [22]. A key contribution in this field of research came from the work by Sartore-Bianchi [23], which identified activating mutations in the lipid kinase PIK3CA gene as an independent biomarker for the unresponsiveness of KRAS WT mCRC to anti-EGFR mAbs. In fact, the authors found that patients with PIK3CA mutations in exons 9 and 20 did not achieve objective tumor response after treatment with panitumumab or cetuximab. In the same period, Prenen and colleagues [24] did not confirm the role of PIK3CA mutations in predicting the resistance to anti-EGFR therapies. In fact, in a group of $200 \mathrm{mCRC}$ patients treated with cetuximab, the authors did not find a correlation between PIK3CA mutations and resistance to the treatment, since the percentage of patients with PIK3CA mutations was almost the same in responders and non-responders. At the same time, in selected KRAS WT patients, the response rate of patients with PIK3CA mutations was superimposable to that bearing PIK3CA WT.

Finally, the role of PTEN/PIK3CA as independent predictive marker of response to anti-EGFR mAbs has been difficult to establish since loss of PTEN and mutations in PIK3CA are frequently associated with mutations in KRAS or BRAF [20]. Thus, on the basis of current knowledge, it is possible to affirm that the combination of mutation of PIK3CA (namely exon 20) and PTEN loss with the BRAF mutation predict a worse outcome in a context of KRAS WT mCRC patients [25]. At the same time, a very large Italian study demonstrated that patients with KRAS, NRAS, BRAF, and PIK3CA WT genes (quadruple WT tumors) have the greatest benefit from chemotherapy plus cetuximab with respect to patients with a mutation in at least one of these genes [26].

In conclusion, this is an expanding research field, and additional mechanisms of mCRC resistance to EGFR blockades are under investigation. Findings from these innovative studies may help to better define the subset of patients who benefit from anti-EGFR therapy.

\section{Secondary Resistance to Anti-EGFR Treatment}

A major problem in the context of mCRC management is that despite the initial response to the anti-EGFR therapy of RAS-BRAF WT patients, the onset of relapse of the disease has been observed in these patients following the acquisition of the so-called secondary or acquired resistance to anti-EGFR mAbs treatment.

Both primary and, particularly, secondary resistance are characterized by an intrinsic genetic intraand inter-tumor heterogeneity, thus highlighting that the knowledge of the molecular landscape of $\mathrm{mCRC}$ is necessary for identifying new and more effective treatments for $\mathrm{mCRC}$ [27]. In particular, the discovery of circulating DNA (ctDNA), molecules of DNA released by tumor cells in the blood of cancer patients, paved the way to the development of a novel and more sensitive diagnostic/prognostic tool to detect, in a rapid and non-invasive manner, molecular abnormalities accounting for resistance to anti-EGFR therapy [28]. Importantly, the analysis of ctDNA in the blood of patients is undoubtedly advantageous respect to biopsy procedures, in terms both of less invasiveness and ethical issues, which limit the number of further biopsies. Moreover, it has been reported that the genetic profile of tumors can change in the course of therapy and that the molecular characteristics of primary tumors and metastases are not always concordant and can change during the course of the disease due to intrinsic molecular cancer heterogeneity [29,30]. The importance of the use of liquid biopsy in the identification of mechanisms involved in the development of resistance to anti-EGFR mAbs was demonstrated in two seminal papers in which KRAS mutations was detected in the serum of KRAS WT patients who developed resistance to cetuximab or panitumumab treatment [31,32].

To the best of our knowledge, the first paper in which an extensive characterization of acquired resistance of $\mathrm{mCRC}$ to anti-EGFR mAbs was performed by analyzing ctDNA in the blood of patients was published by Pietrantonio and co-workers [33]. These authors investigated group of patients who initially responded to cetuximab or panitumumab-based treatment but subsequently elicited a radiologically-documented disease progression. Tissue samples were analyzed with a next-generation sequencing (NGS) panel that includes 50 genes' hotspot regions and with in situ hybridization and immunohistochemistry. At the same time, liquid biopsy was performed on plasma, and Droplet Digital 
PCR was used to identify mutant DNA alleles. The authors reported the presence of $R A S$ mutations and HER2/MET amplification detected at high frequency in both tissue and blood sample analysis. On the other hand, mutations in BRAF and PIK3CA were rare in tissue and liquid biopsies, thus suggesting that the PIK3CA/AKT/mTOR pathway could be less crucial for the development of acquired resistance to anti-EGFR mAbs treatment. In comparison to the biopsy, in some cases, mutations in ctDNA were detected at very low levels, suggesting that only a small fraction of tumor cells release DNA as a consequence of heterogeneous resistance mechanisms. The authors concluded that a combination of tumor and liquid biopsies could help to better characterize the mechanism of acquired resistance to anti-EGFR mAbs. It is of note that the heterogeneity of intra-lesion and inter-lesion reinforces the concept that the liquid biopsy could represents a promising method to identify genetic alterations that account for the acquired resistance of mCRC [34-36]. Anyway, due to several concerns that need to be addressed before liquid biopsies could be translated into clinical application [37,38], conventional biopsies still remain the gold standard for patient evaluation.

\section{Advanced Preclinical Models and Omics in the Discovery of New Strategies against mCRC}

The described progress in the knowledge of resistance mechanisms characterizing mCRC needs the development of novel and more effective therapeutic strategies. In this view, preclinical research plays a fundamental and irreplaceable role. To date, a major limit of translational medicine is that less than $5 \%$ of compounds selected in preclinical studies are really effective and sufficiently safe in clinical trials. There could be several reasons for this high drug attrition rates, but there is a consensus that these limits may be bypassed through the introduction of advanced preclinical models [39].

Established cell lines have contributed to the understanding of the biological and molecular bases of cancer, leading to the identification of effective compounds still employed in clinical practice [40]. A drawback of this model is that in the preclinical studies, only a limited number of cell lines can be employed (usually less than 10), thus limiting the possibility to reproduce a genetic diversity that is typical of patients. An intelligent strategy to overcome this limit was proposed by Medico and colleagues [41]. The authors generated a large panel of established cell lines whose molecular profile was able to entirely cover the clinical features of CRC [42]. In particular, they demonstrated that the most common mutations observed in clinical specimens (e.g., KRAS, NRAS, BRAF, PIK3CA, and PTEN) were present with the same mutational rate in the selected cell lines. Importantly, the cell lines matched the sensitivity or resistance to anti-EGFR mAbs according to mutational status reported in clinical studies. Notably, this cell collection permitted the authors to demonstrate that the targeting of alterations in kinase genes such as ALK, FGFR2, NTRK1/2, and RET (commonly observed in patients unresponsive to anti-EGF Abs) would represent a valid therapeutic strategy against mCRC. Very recently, the same group [43] confirmed their findings in a panel of 29 CRC lines (defined by the authors as xeno-cell lines-XL) derived from a cohort of CRC PDXs obtained by implanting fresh specimens from primary tumors or metastases. Moreover, using these experimental models, the authors validated ERBB2 as possible therapeutic targets sensitive to treatment with lapatinib and trastuzumab [43]. Importantly, this drug combination was proven to be effective against metastatic HER2 ${ }^{+}$CRC in a phase II clinical trial [44].

However, even though the selected collection of cell lines resembles the genetic and transcriptional alterations present in human tumors, these cells grow as a monolayer in a two-dimensional (2D) system and fail to mimic in vivo conditions because most of physiologic characteristics of tumors-including biochemical networks, cell-to-cell interactions, and cell-to-matrix interactions-are lost. There are several papers demonstrating that the culture of tumor cells in a three-dimensional (3D) system, otherwise said spheroids or tumoroids, are biologically relevant for preclinical drug development. Moreover, since tumor cells interact with extracellular matrix (ECM) and tumor stroma in 3D system, the signaling pathway could be influenced because it occurs in tumors in situ $[45,46]$.

In a recent work aimed at identifying biomarkers of sensitivity to anti-EGFR treatment [47], Schütte and co-workers proposed an experimental platform called OncoTrack (OT), derived from a 
large biobank of 106 CRC that includes 35 organoids and 59 PDXs, from which nineteen tumors were modelled in both systems. By using multiple sequencing approaches (i.e., whole genome, exome, and RNA sequencing), they observed that the genetic profiles of the models were generally concordant with their matched donor tumors; in some cases, divergences due to the intra-tumor heterogeneity were observed.

A limit of the PDX model is that it does not mimic the stages of CRC growth and progression, since tumors are implanted in unnatural heterotopic site (usually the subcutis of the back of mice), and it is well-know that metastatic dissemination is not observed. In contrast, the exploitation of the full potential of a new therapy against mCRC should rely on the orthotopical implantation of tumors in the colon, which could better represent the human clinical situation, both in terms of site of the origin of CRC and in the metastatic spreading.

Several authors have successfully demonstrated the feasibility of this strategy, which permits to follow primary tumor's growth, metastatic dissemination and efficacy of therapeutics by in vivo imaging.

In particular, the Hoffman's group developed orthotopic models of mCRC via the implantation of human tumor tissues into the serosa of the cecum of immunosuppressed mice. The growth of primary tumors and spontaneous metastases were visualized by the use fluorophore-conjugated anti-CEA antibodies [48] or by transfecting cells with green or red fluorescence protein [49,50]. This technology represents a very potent tool for the identification of the anticancer activity of new therapeutic approaches.

In order to study the role of the most common mutations associated with the metastatic dissemination of CRC and to dissect the adenoma-carcinoma sequence of CRC, the Van Rheenen's group developed a model of spontaneous metastases in mice through the orthotopic injection in the cecum of mice of organoids engineered to harbor different combinations of CRC mutations [51,52]. They found that this model mimicked the human CRC condition because primary tumors exhibited a long latency period, and tumor cells were capable of invading the blood circulation and forming metastases at distant sites. Moreover, the real time imaging by intravital microscopy and bioluminescence allowed for the visualization of in vivo tumor cell dynamics. In particular, they generated human CRC organoids with a combination of mutations of the four most frequently gene alterations reported in CRC by using CRISPR/Cas9 genome editing, such as KRAS G12D mutation and the knockout of APC, P53, and SMAD4, while WNT, EGFR, P53, and TGF- $\beta$ were present in the normal status. By using this technology, they obtained a number of so-called quadruple-mutant organoids in which one of the four genes was in the WT form and the other three were in mutated forms. Their results demonstrated that the co-presence of mutations in the four genes accelerated the growth of tumors, favored cell migration and the formation of metastases at distant sites, including the liver.

Other groups, using organoids derived from genetically engineered mouse models (GEMMs), WT organoids engineered ex vivo, and patient-derived human CRC organoids, have demonstrated that the orthotopic implantation of CRC in animals recapitulates CRC progression in humans and could be used to investigate the potential of new therapeutics for mCRC [53].

The key question about the ability of experimental systems used to predict the response of humans to therapeutics remains to be solved. In this regard, Vlachogiannis and colleagues [54] approached this problem for a large biobank of metastatic gastrointestinal tumors including mCRC and compared the results obtained in ex vivo organoids and patient-derived orthotopic xenografts (PDOXs) with the response to anticancer therapeutics in clinical trials. Their results obtained by NGS, whole genome sequencing and transcriptomic analysis showed a high concordance between parental biopsies and organoids at successive passages of organoids in culture, and they confirmed that organoids maintain the profile of the original human tumors, with a $96 \%$ overlap in the mutational spectrum. Moreover, the response of both organoids and of PDOXs to regorafenib matched the sensitivity or resistance observed in patients, thus confirming the predictive value of these models. 
The use of organoids and their implantation in animal models is an expanding field of investigation in preclinical research [55], but for the extensive application of this platform in personalized medicine, the implementation of studies that demonstrate the concordance between preclinical response and patient outcomes is necessary.

Overall, it is possible to assert that the currently available pre-clinical models (ranging from established cell lines in vitro to the most advanced in vivo models) are distinguished by a number of characteristics that make them unique and irreplaceable (Figure 1). However, since none of these experimental models are capable of fully recapitulating the complexity of human cancer, the most valuable strategy to improve our knowledges is to combine multiple experimental approaches and then integrate the obtained results.
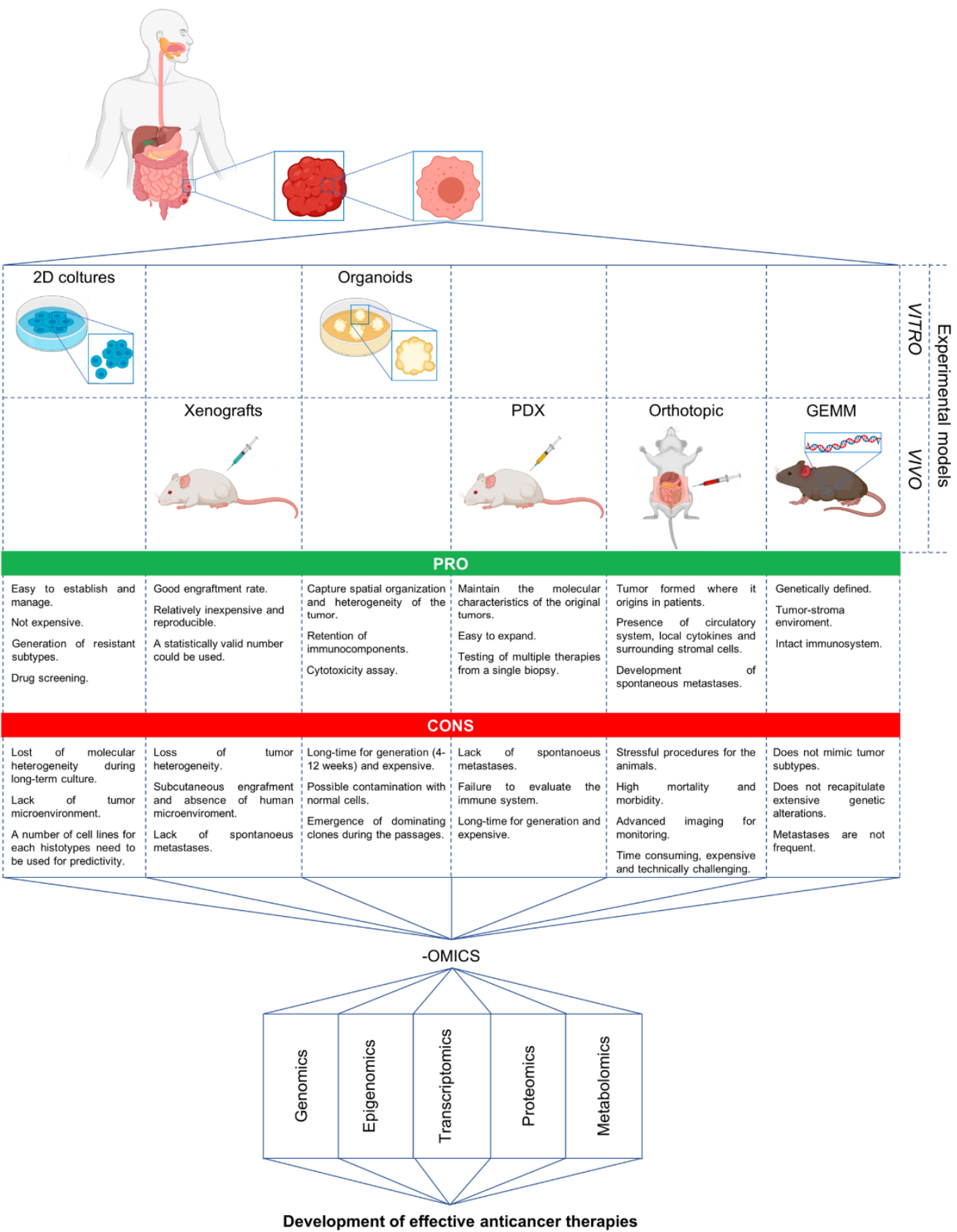

Figure 1. Schematic representation showing the main experimental models and OMICS approaches that can be integrated for the development of effective anticancer drugs. This figure was created with BioRender.com. 


\section{Development of Novel Therapeutics in Targeting mCRC: The Experience of Our Laboratory}

In the last decade, several new molecules have been investigated for their antitumoral activity against mCRC that is resistant to standard therapies. In this view, G-quadruplex (G4)-ligands-a class of small molecules able to bind and stabilize non-canonical secondary structures of nucleic acids-has received particular attention. Indeed, a number of studies from our and other laboratories have shown that these molecules exert potent antitumoral activity [56-59]. Recently, we demonstrated that EMICORON, a G4 ligand synthetized in our laboratory, is effective in the treatment of mCRC [60]. In particular, by using advanced CRC preclinical models (i.e., PDX and orthotopic models), we showed that EMICORON is able to inhibit the growth of primary tumors and to negatively affect the dissemination of tumor cells to lymph nodes, the intestine, the stomach and the liver, presenting a potent antitumoral activity while exhibiting a very favorable toxicological profile [60,61].

In subsequent studies, we found that PDXs originating from the same patient can show different responses to treatment with EMICORON. Indeed, while some mice showed a complete remission, in others, there was no-response or an initial response followed by disease recurrence and rapid progression [62], reflecting the heterogeneity within the tumor of origin.

Starting from these results, we are now pointing at defining the mechanism(s) underlying the responsiveness/resistance of colorectal cancer to EMICORON. Nowadays, large-scale analyses-the so-called omics approaches-represent the most potent tools to obtain a comprehensive understanding of tumor biology and, in particular, of all those mechanisms participating in tumor formation, development, dissemination, and drug resistance. Based on these considerations and knowing that G4-ligands can affect the expression of genes containing G4 structures within (or in proximity of) their promoter, we performed an extensive analysis of gene expression based on the TaqMan OpenArray (Life Technologies, Thermo Fisher Scientific Corporation, Foster City, CA, USA). The analysis, performed on a panel of 624 genes, provided extensive information regarding the transcriptional profile of tumor cells treated with EMICORON. Conscious of the importance of adopting multiple investigation models, experiments were performed on both RNA extracted from PDXs and established CRC cell lines.

The first set of analyses performed on PDXs with a complete response to EMICORON (Figure 2A) showed that EMICORON affected the expression of 163 genes ( 30 up-regulated and 133 down-regulated). Subsequently, the analyses were also extended to unresponsive PDXs. This second set of data evidenced the up-regulation of 179 genes and the down-regulation of 74 genes (Figure 2B).

In order to identify the genes really modulated by EMICORON, the results of the two experiments were matched, and the genes common to the two analyses were subtracted from the list of genes modulated in the responder PDXs (Figure 3A,B). Based on this criterion, the number of genes putatively affected by EMICORON treatment dropped to 82 (11 up-regulated and 71 down-regulated genes; see Figure 3A,B).

Transcriptional analyses were then extended also to HCT116, a well-established CRC cell line. Interestingly, the results of OpenArray identified 153 genes (67 up-regulated and 86 down regulated) modulated in response to EMICORON treatment ( $1 \mu \mathrm{M}$ for $24 \mathrm{~h}$ ) (Figure $2 \mathrm{C})$. Since these results were reasonably different from those obtained in the PDXs, the genes modulated in the HCT116 cells were compared with those resulting from the first analysis, and the sole common genes were selected (Figure 3C,D). Through these analyses, five up-regulated and 19 down-regulated genes, currently under validation, were finally identified. 
A
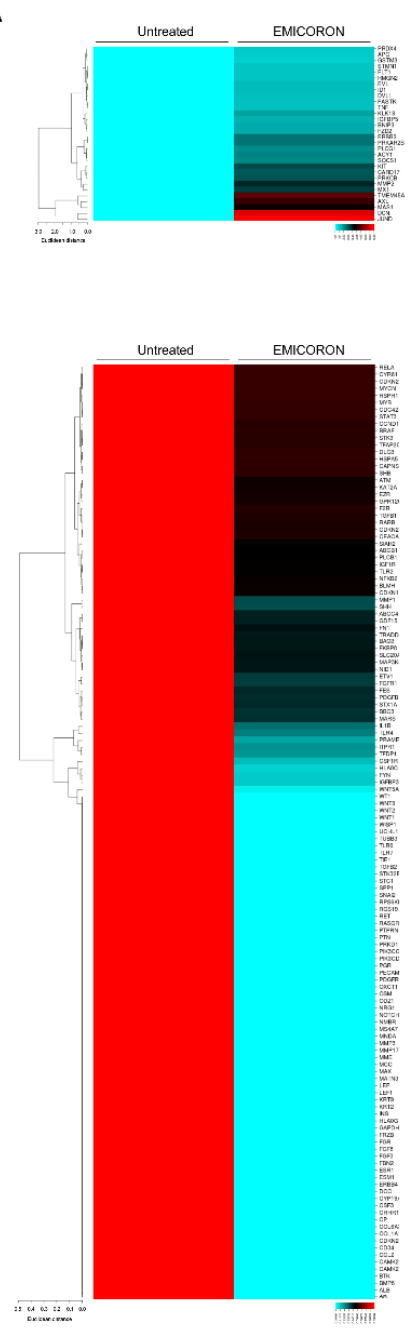
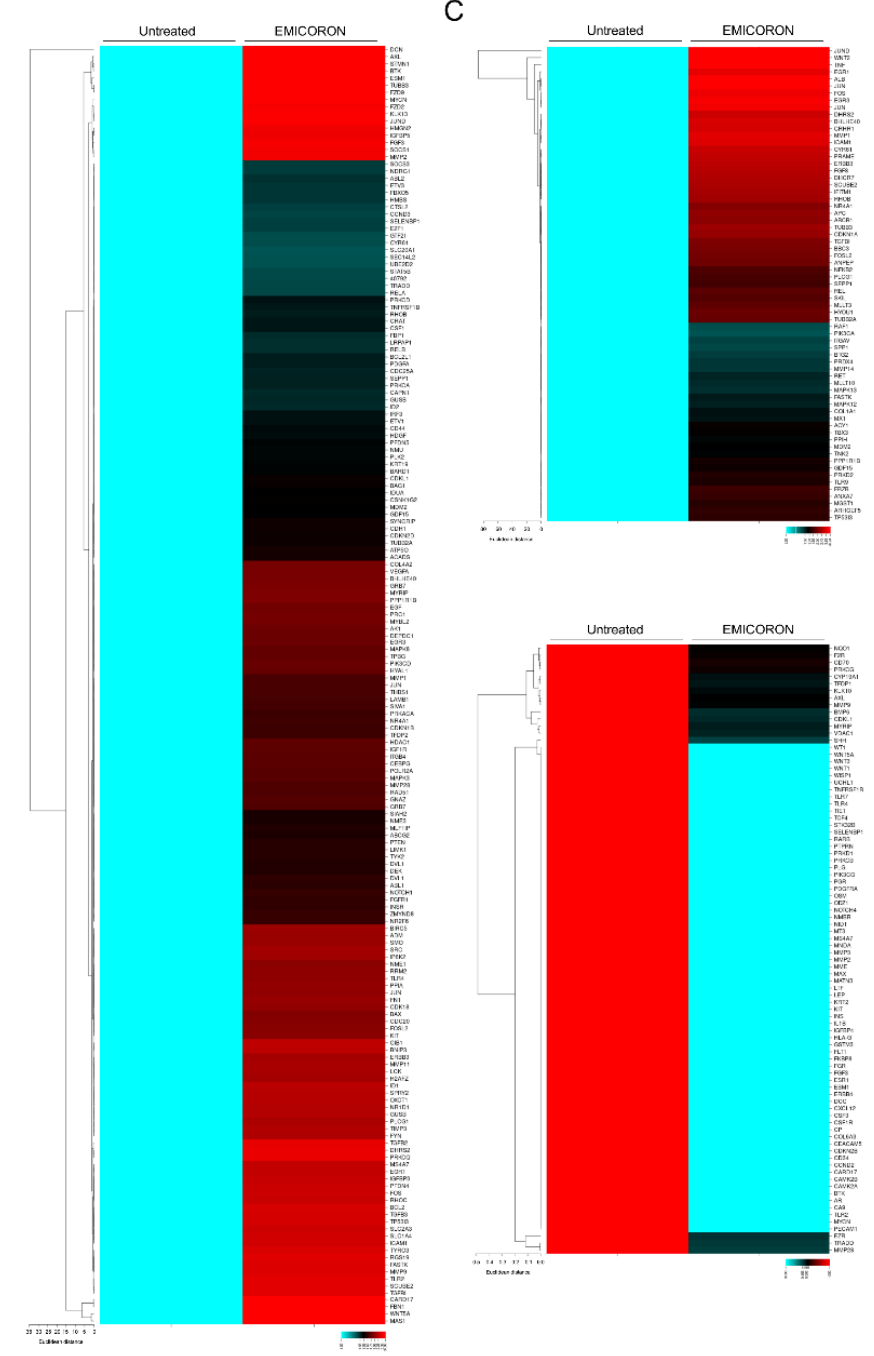

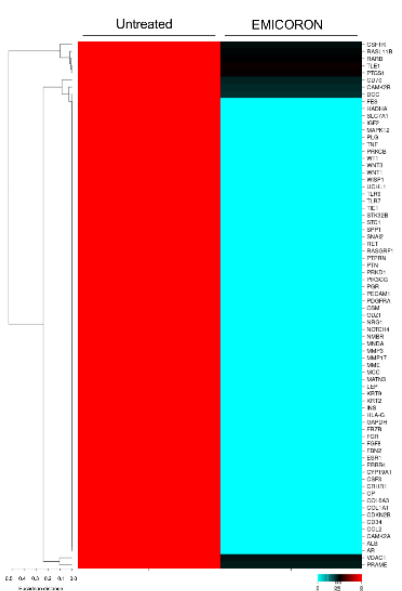

Figure 2. Gene expression analysis in patient-derived-xenografts (PDXs) and in HCT116 cells treated with EMICORON. (A) Heatmap representation of cancer-related genes analyzed by TaqMan OpenArray that were up-regulated (upper panel) or down-regulated genes (lower panel) in a responder PDX mouse model treated or untreated with EMICORON. (B) Heatmap representation of cancer-related genes analyzed by TaqMan OpenArray that were up-regulated (upper panel) or down-regulated genes (lower panel) in a non-responder PDX mouse model treated or untreated with EMICORON. (C) Heatmap representation of cancer-related genes analyzed by TaqMan OpenArray that were up-regulated (upper panel) or down-regulated genes (lower panel) in HCT116 cells that were treated or untreated with EMICORON. 
PDX responder

$\odot$ PDX non responder

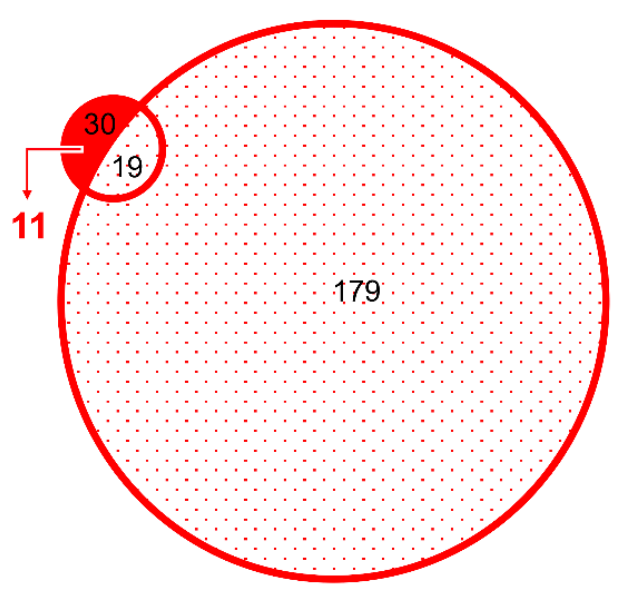

C

PDX responder - PDX non responder O HCT116 cells

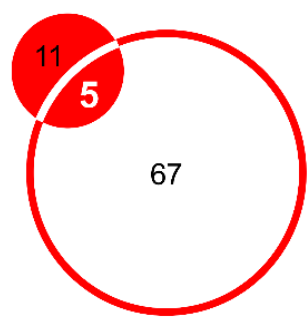

ACY1_Hs00167402_m1 APC_Hs00181051_m1 MX1_Hs00895608_m1 PRDX4_Hs00197394_m1 TNF_Hs00174128_m1
PDX responder (133 genes)

(.) PDX non responder (74 genes)

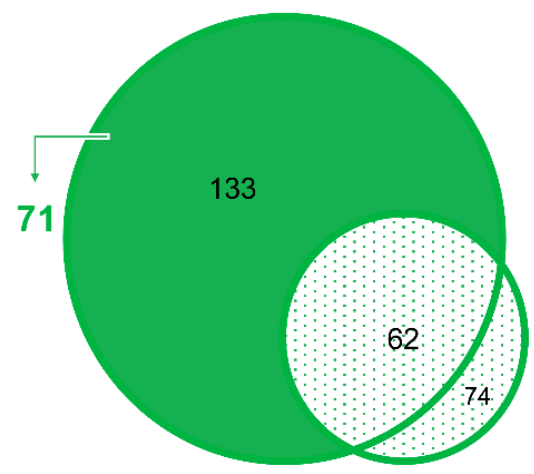

D

PDX responder - PDX non responder HCT116 cells

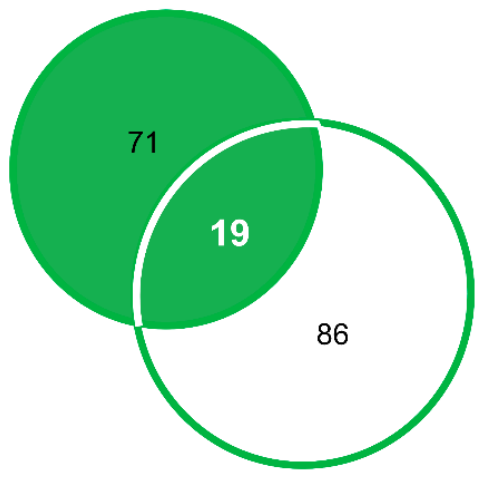

MS4A7_Hs00960227_m1 MYCN Hs00232074 m1 NID1_Hs00159600_m1 SHH_Hs00179843_m1 TFDP1_Hs00830594_s1 TLR2_Hs01014511_m1 TLR4_Hs00152939_m1 TRADD_Hs00182558_m1 WNT5A_Hs00998537_m1

Figure 3. Selection of target genes of EMICORON. (A) Venn diagrams showing the overlap between the genes up-regulated in the responder and non-responder PDX models following treatment with EMICORON (given orally at $15 \mathrm{mg} / \mathrm{kg} /$ mouse daily for two consecutive weeks). Eleven genes selectively upregulated in the responder mouse were selected as targets of EMICORON. (B) Venn diagrams showing the overlap between the genes down-regulated in the responder and non-responder PDXs treated with EMICORON (as above reported). The analysis identified 71 genes targets of EMICORON. (C) Venn diagrams showing the overlap between the genes selected in the panel A and the genes up-regulated in the HCT116 cells treated with EMICORON ( $1 \mu \mathrm{M}$ for $24 \mathrm{~h})$. The analysis identified 5 common genes that were selected as targets of EMICORON. (D) Venn diagrams showing the overlap between the genes selected in the panel B and the genes down-regulated in the HCT116 cells treated with EMICORON (1 $\mu \mathrm{M}$ for $24 \mathrm{~h}$ ). The analysis identified 19 common genes selected as targets of EMICORON. 
To establish an order of priority in targets' validation, all the genes modulated in response to EMICORON were analyzed by QGRS Mapper (http://bioinformatics.ramapo.edu/QGRS/index.php), a bioinformatic tool used for the identification of nucleotide sequences able to generate potential $\mathrm{G} 4$ structures. The analyses, carried on a region of $1000 \mathrm{bp}$ upstream of the transcription starting site, revealed that three out of five up-regulated genes (ACY1, MX1, and PRDX4) and 11 out of 19 down-regulated genes (BMP6, BTK, EZR, F2R, FGF3, MYCN, NID1, SHH, TLR2, TRADD, and WNT5A) contain at least one putative $G 4$ within their promoter, a structural characteristic that would justify the transcriptional control exerted by EMICORON treatment (Figure 3C,D). Based on the data available in the literature, genes known to play a relevant role in CRC will be selected for future studies. In particular, some genes that seem to be promising for their potential as molecular target in $\mathrm{mCRC}$ are detailed below.

The BTK (Bruton's tyrosine kinase) is a non-receptor tyrosine kinase that is constitutively expressed in B cells, where it plays a key role in promoting the maturation, differentiation, and proliferation of $B$ lymphocytes [63]. Ibrutinib—a BTK-specific inhibitor—was found to be effective against some types of lymphoma and chronic lymphocytic leukemia, also in combination with chemotherapeutics $[64,65]$. Recently, the overexpression of BTK has been detected in various solid tumors and has been found to be associated with worse prognoses [66]. In particular, a new BTK isoform, p65BTK, has been found to be abundantly expressed in CRC where, acting downstream of the RAS/MAPK pathway, it plays a role as mediator of RAS-induced transformation [67]. Interestingly, BTK inhibition re-sensitizes drug-resistant colon cancer cell lines, organoids, and xenografts lacking TP53 in 5-fluorouracil [68]. Therefore, these evidences could suggest that BTK could be a promising new target in CRC tumors that are resistant to conventional therapy.

Ezrin is a member of the ezrin-radixin-moesin (ERM) family of proteins, which link the actin-containing cytoskeleton to plasma membrane proteins and activate the actin cytoskeleton [69]. Ezrin plays a role in tumorigenesis, invasion, and metastatic processes in a variety of human cancers including colorectal cancer [70]. In a proteomic analysis, ezrin was described as the most promising candidate predictive marker for predicting lymph node metastasis in CRC [71].

Wnt5a is a member of the non-canonical Wnt signaling ( $\beta$-catenin-independent) pathway involved in a variety of cellular processes [72]. The aberrant activation or inhibition of Wnt5a signaling is emerging as an important event in tumorigenesis, exerting both oncogenic and tumor suppressive effects in cancer. While Wnt5a activation has been shown to inhibit the cell growth, migration, and invasiveness of thyroid and CRC cells [73], increased Wnt5a expression is involved in the aggressiveness of other types of cancers [74]. The tumor suppressor effects of Wnt5a may be achieved by antagonizing canonical Wnt signaling, resulting in the inhibition of cell growth and migration [75]. Another study showed that Wnt5a expression stimulated the directional migration and invasion of colon cancer cells and was correlated with poor prognoses [76]. Further research is needed clarify this apparent discrepancy about the role of Wnt5a signaling in colon cancer.

Moreover, Wnt5a is one endogenous mediator that has been implicated in driving the molecular mechanism of innate tolerance [77]. Mehmeti described the binding of Wnt5a to toll-like receptor 2 (TLR2) under inflammatory conditions. The Wnt5a/TLR2-induced signal promotes the induction of the immunosuppressive cytokine IL-10 in human or pro-inflammatory TNF $\alpha$ in mice [78]. TLRs are overexpressed in some carcinomas, leading to their exploration as prognostic markers and targets for oncological treatment [79]. Interestingly, in our analysis, we observed the downregulation of TLR2, suggesting a link between Wnt5a/TLR2 and EMICORON activity. Moreover, two upregulated genes seem to be promising: peroxiredoxin 4 (PRDX4) and aminoacylase 1 (ACY1).

PRDX4 is a member of peroxiredoxin family involved in a cellular endogenous defense system against ROS, especially in catalyzing peroxide reduction to eliminate excessive cellular $\mathrm{H} 2 \mathrm{O} 2$. PRDX4 plays key roles in several cellular functions. It is a multifunctional protein that is involved in protection against oxidative injury, the regulation of cell proliferation, and the modulation of intracellular signaling, and it has also been associated with the pathogenesis of tumors [80]. 
Moreover, PRDX4 limits inflammation by directly regulating IL-1 $\beta$ generation via the inactivation of caspase-1 activity [81].

PRDX4 has been reported to be over-expressed in CRC and its levels are tightly related to lymph-nodes' metastases [82]. Conversely, another study identified that the enhanced expression of PRDX4 is associated with the curcumin-enhancing efficacy of the irinotecan-induced apoptosis of colorectal cancer LOVO cells [83].

ACY1 is a cytosolic enzyme that deacylates the $\alpha$-acylated amino acid from the $\mathrm{N}$-terminal peptide of intracellular proteins [84]. In addition to its function, ACY1 has been studied in different types of human cancer. In small cell lung cancer (SCLC), liver cancer, and renal cell carcinoma, ACY1 expression has been significantly reduced [85], suggesting that ACY1, in these tumors, acts as tumor suppressor. The role of ACY1 in CRC remains unclear. Bing and co-workers [86] observed that the level of ACY1 mRNA and protein is positively associated with the TNM stage, and the inhibition of ACY1 expression leads to the reduction of proliferation and the increase of apoptosis in CRC cells. These results indicate that in CRC, ACY1 has a tumor-promoting function. A further evaluation of ACY1 could lead to its identification as a clinically useful prognostic marker and a potential therapeutic target for CRC.

Of note, the interests towards these genes could be manifold since they could represent both the direct/indirect effectors of EMICORON activity and druggable targets that are useful for potentiating EMICORON activity.

\section{Conclusions}

The current knowledge of the complexity of cancer and the progress of technologies supports the transition from approaches based on simple models to multi-models that are better able to mimic tumors in patients and to guide for advancements in drug development. Moreover, we now have the opportunity to integrate genomic and transcriptomic analyses with advanced experimental models, even if their potential to predict patient clinical outcomes remains to be established. A critical point is represented by the time and cost required-two aspects that make this approach difficult to be pursued in the early stages of drug development when a large number of drugs are screened. However, in our opinion, the use of next-generation strategies could increase the potential success of investigational compounds and should be considered in later stages of preclinical studies, before entering clinical phases.

In conclusion, the integration of omics and advanced mouse models of mCRC with more clinical-like criteria of the evaluation of antitumor efficacy in preclinical studies, could accelerate the anticancer discovery process and provide new weapons against cancer.

Author Contributions: Conceptualization and design: A.B. and C.L.; data collection: M.P., P.Z., N.P., and A.A.; data analysis and interpretation: all the authors; writing-original draft: M.P., P.Z., and C.L.; writing-review and editing: A.B., N.P., and A.A. All authors have read and agreed to the published version of the manuscript.

Funding: This research and the APC were funded by the Italian Association for Cancer Research (AIRC), IG grant 18637 (CL) and by an intramural grant-in-aid funded by the Italian Ministry of Health (MP and PZ).

Acknowledgments: We are grateful to Adele Petricca for secretarial assistance.

Conflicts of Interest: The authors declare no conflict of interest.

\section{References}

1. Bray, F.; Ferlay, J.; Soerjomataram, I.; Siegel, R.L.; Torre, L.A.; Jemal, A. Global Cancer Statistics 2018: Globocan Estimates of Incidence and Mortality Worldwide for 36 Cancers in 185 Countries. CA Cancer J. Clin. 2018, 68, 394-424. [CrossRef]

2. Van Cutsem, E.; Cervantes, A.; Adam, R.; Sobrero, A.; van Krieken, J.H.; Aderka, D.; Aguilar, E.A.; Bardelli, A.; Benson, A.; Bodoky, G.; et al. Esmo Consensus Guidelines for the Management of Patients with Metastatic Colorectal Cancer. Ann. Oncol. 2016, 27, 1386-1422. [CrossRef] [PubMed]

3. Cohen, R.B. Epidermal Growth Factor Receptor as a Therapeutic Target in Colorectal Cancer. Clin. Colorectal Cancer 2003, 2, 246-251. [CrossRef] 
4. Galizia, G.; Lieto, E.; de Vita, F.; Orditura, M.; Castellano, P.; Troiani, T.; Imperatore, V.; Ciardiello, F. Cetuximab, a Chimeric Human Mouse Anti-Epidermal Growth Factor Receptor Monoclonal Antibody, in the Treatment of Human Colorectal Cancer. Oncogene 2007, 26, 3654-3660. [CrossRef]

5. Benvenuti, S.; Sartore-Bianchi, A.; di Nicolantonio, F.; Zanon, C.; Moroni, M.; Veronese, S.; Siena, S.; Bardelli, A. Oncogenic Activation of the Ras/Raf Signaling Pathway Impairs the Response of Metastatic Colorectal Cancers to Anti-Epidermal Growth Factor Receptor Antibody Therapies. Cancer Res. 2007, 67, 2643-2648. [CrossRef] [PubMed]

6. Lievre, A.; Bachet, J.B.; le Corre, D.; Boige, V.; Landi, B.; Emile, J.F.; Cote, J.F.; Tomasic, G.; Penna, C.; Ducreux, M.; et al. Kras Mutation Status Is Predictive of Response to Cetuximab Therapy in Colorectal Cancer. Cancer Res. 2006, 66, 3992-3995. [CrossRef] [PubMed]

7. Baselga, J. The Egfr as a Target for Anticancer Therapy-Focus on Cetuximab. Eur. J. Cancer 2001, 37 (Suppl. 4), S16-S22. [CrossRef]

8. Davies, H.; Bignell, G.R.; Cox, C.; Stephens, P.; Edkins, S.; Clegg, S.; Teague, J.; Woffendin, H.; Garnett, M.J.; Bottomley, W.; et al. Mutations of the Braf Gene in Human Cancer. Nature 2002, 417, 949-954. [CrossRef]

9. Di Nicolantonio, F.; Martini, M.; Molinari, F.; Sartore-Bianchi, A.; Arena, S.; Saletti, P.; de Dosso, S.; Mazzucchelli, L.; Frattini, M.; Siena, S.; et al. Wild-Type Braf Is Required for Response to Panitumumab or Cetuximab in Metastatic Colorectal Cancer. J. Clin. Oncol. 2008, 26, 5705-5712. [CrossRef]

10. van Brummelen, E.M.J.; de Boer, A.; Beijnen, J.H.; Schellens, J.H.M. Braf Mutations as Predictive Biomarker for Response to Anti-Egfr Monoclonal Antibodies. Oncologist 2017, 22, 864-872. [CrossRef]

11. Cancer Genome Atlas, Network. Comprehensive Molecular Characterization of Human Colon and Rectal Cancer. Nature 2012, 487, 330-337. [CrossRef] [PubMed]

12. Bertotti, A.; Migliardi, G.; Galimi, F.; Sassi, F.; Torti, D.; Isella, C.; Cora, D.; di Nicolantonio, F.; Buscarino, M.; Petti, C.; et al. A Molecularly Annotated Platform of Patient-Derived Xenografts ("Xenopatients") Identifies Her2 as an Effective Therapeutic Target in Cetuximab-Resistant Colorectal Cancer. Cancer Discov. 2011, 1, 508-523. [CrossRef] [PubMed]

13. Kavuri, S.M.; Jain, N.; Galimi, F.; Cottino, F.; Leto, S.M.; Migliardi, G.; Searleman, A.; Shen, W.; Monsey, J.; Trusolino, L.; et al. HER2 activating mutations are targets for colorectal cancer treatment. Cancer Discov. 2015, 5, 832-841. [CrossRef] [PubMed]

14. Bregni, G.; Sciallero, S.; Sobrero, A. HER2 Amplification and Anti-EGFR Sensitivity in Advanced Colorectal Cancer. JAMA Oncol. 2019, 5, 605-606. [CrossRef] [PubMed]

15. Trusolino, L.; Comoglio, P.M. Scatter-factor and semaphorin receptors: Cell signalling for invasive growth. Nat. Rev. Cancer 2002, 2, 289-300. [CrossRef]

16. Lee, H.E.; Kim, M.A.; Lee, H.S.; Jung, E.-J.; Yang, H.-K.; Lee, B.L.; Bang, Y.-J.; Kim, W.H. MET in gastric carcinomas: Comparison between protein expression and gene copy number and impact on clinical outcome. Br. J. Cancer 2012, 107, 325-333. [CrossRef]

17. Bardelli, A.; Corso, S.; Bertotti, A.; Hobor, S.; Valtorta, E.; Siravegna, G.; Sartore-Bianchi, A.; Scala, E.; Cassingena, A.; Zecchin, D.; et al. Amplification of the MET receptor drives resistance to anti-EGFR therapies in colorectal cancer. Cancer Discov. 2013, 3, 658-673. [CrossRef]

18. Thomas, S.M.; Grandis, J.R. Pharmacokinetic and pharmacodynamic properties of EGFR inhibitors under clinical investigation. Cancer Treat. Rev. 2004, 30, 255-268. [CrossRef]

19. Frattini, M.; Saletti, P.; Romagnani, E.; Martin, V.; Molinari, F.; Ghisletta, M.; Camponovo, A.; Etienne, L.L.; Cavalli, F.; Mazzucchelli, L. PTEN loss of expression predicts cetuximab efficacy in metastatic colorectal cancer patients. Br. J. Cancer 2007, 97, 1139-1145. [CrossRef]

20. Karapetis, C.; Jonker, D.; Daneshmand, M.; Hanson, J.E.; O'Callaghan, C.J.; Marginean, C.; Zalcberg, J.R.; Simes, J.; Moore, M.J.; Tebbutt, N.C.; et al. PIK3CA, BRAF, and PTEN Status and Benefit from Cetuximab in the Treatment of Advanced Colorectal Cancer-Results from NCIC CTG/AGITG CO.17. Clin. Cancer Res. 2013, 20, 744-753. [CrossRef]

21. Samuels, Y. High Frequency of Mutations of the PIK3CA Gene in Human Cancers. Science 2004, $304,554$. [CrossRef] [PubMed]

22. Ligresti, G.; Militello, L.; Steelman, L.S.; Cavallaro, A.; Basile, F.; Nicoletti, F.; Stivala, F.; McCubrey, J.A.; Libra, M. PIK3CA mutations in human solid tumors. Cell Cycle 2009, 8, 1352-1358. [CrossRef] [PubMed] 
23. Sartore-Bianchi, A.; Martini, M.; Molinari, F.; Veronese, S.M.; Nichelatti, M.; Artale, S.; Di Nicolantonio, F.; Saletti, P.; De Dosso, S.; Mazzucchelli, L.; et al. PIK3CA Mutations in Colorectal Cancer Are Associated with Clinical Resistance to EGFR-Targeted Monoclonal Antibodies. Cancer Res. 2009, 69, 1851-1857. [CrossRef] [PubMed]

24. Prenen, H.; De Schutter, J.; Jacobs, B.; De Roock, W.; Biesmans, B.; Claes, B.; Lambrechts, D.; Van Cutsem, E.; Tejpar, S. PIK3CA Mutations Are Not a Major Determinant of Resistance to the Epidermal Growth Factor Receptor Inhibitor Cetuximab in Metastatic Colorectal Cancer. Clin. Cancer Res. 2009, 15, 3184-3188. [CrossRef] [PubMed]

25. Yang, Z.Y.; Wu, X.Y.; Huang, Y.F.; Di, M.Y.; Zheng, D.Y.; Chen, J.Z.; Ding, H.; Mao, C.; Tang, J.L. Promising Biomarkers for Predicting the Outcomes of Patients with Kras Wild-Type Metastatic Colorectal Cancer Treated with Anti-Epidermal Growth Factor Receptor Monoclonal Antibodies: A Systematic Review with Meta-Analysis. Int. J. Cancer 2013, 133, 1914-1925. [CrossRef]

26. Normanno, N.; Rachiglio, A.M.; Lambiase, M.; Martinelli, E.; Fenizia, F.; Esposito, C.; Roma, C.; Troiani, T.; Rizzi, D.; Tatangelo, F.; et al. Heterogeneity of KRAS, NRAS, BRAF and PIK3CA mutations in metastatic colorectal cancer and potential effects on therapy in the CAPRI GOIM trial. Ann. Oncol. 2015, 26, 1710-1714. [CrossRef]

27. Misale, S.; Di Nicolantonio, F.; Sartore-Bianchi, A.; Siena, S.; Bardelli, A. Resistance to Anti-EGFR Therapy in Colorectal Cancer: From Heterogeneity to Convergent Evolution. Cancer Discov. 2014, 4, 1269-1280. [CrossRef]

28. Diehl, F.; Schmidt, K.; Choti, M.A.; Romans, K.; Goodman, S.; Li, M.; Thornton, K.; Agrawal, N.; Sokoll, L.; Szabo, S.A.; et al. Circulating mutant DNA to assess tumor dynamics. Nat. Med. 2008, 14, 985-990. [CrossRef]

29. De Mattos-Arruda, L.; Weigelt, B.; Cortés, J.; Won, H.H.; Ng, C.K.; Nuciforo, P.; Bidard, F.-C.; Aura, C.; Peg, V.; Piscuoglio, S.; et al. Capturing intra-tumor genetic heterogeneity by de novo mutation profiling of circulating cell-free tumor DNA: A proof-of-principle. Ann. Oncol. 2014, 25, 1729-1735. [CrossRef]

30. Siravegna, G.; Lazzari, L.; Crisafulli, G.; Sartore-Bianchi, A.; Mussolin, B.; Cassingena, A.; Martino, C.; Lanman, R.B.; Nagy, R.J.; Fairclough, S.; et al. Radiologic and Genomic Evolution of Individual Metastases during HER2 Blockade in Colorectal Cancer. Cancer Cell 2018, 34, 148-162.e7. [CrossRef]

31. Misale, S.; Yaeger, R.; Hobor, S.; Scala, E.; Janakiraman, M.; Liska, D.; Valtorta, E.; Schiavo, R.; Buscarino, M.; Siravergna, G.; et al. P2.08 Emergence of Kras Mutations and Acquired Resistance to Anti Egfr Therapy in Colorectal Cancer. Ann. Oncol. 2012, 23, v24. [CrossRef]

32. Diaz, L.A., Jr.; Williams, R.T.; Wu, J.; Kinde, I.; Hecht, J.R.; Berlin, J.; Allen, B.; Bozic, I.; Reiter, J.G.; Nowak, M.A.; et al. The molecular evolution of acquired resistance to targeted EGFR blockade in colorectal cancers. Nature 2012, 486, 537-540. [CrossRef]

33. Pietrantonio, F.; Vernieri, C.; Siravegna, G.; Mennitto, A.; Berenato, R.; Perrone, F.; Gloghini, A.; Tamborini, E.; Lonardi, S.; Morano, F.; et al. Heterogeneity of acquired resistance to anti-EGFR monoclonal antibodies in patients with metastatic colorectal cancer. Clin. Cancer Res. 2016, 23, 2414-2422. [CrossRef]

34. Schmiegel, W.H.; Scott, R.J.; Dooley, S.; Lewis, W.; Meldrum, C.J.; Pockney, P.G.; Draganic, B.; Smith, S.; Hewitt, C.; Philimore, H.; et al. Blood-based detection ofRASmutations to guide anti-EGFR therapy in colorectal cancer patients: Concordance of results from circulating tumor DNA and tissue-based Ras testing. Mol. Oncol. 2017, 11, 208-219. [CrossRef] [PubMed]

35. Vidal, J.; Muinelo, L.; Dalmases, A.; Jones, F.; Edelstein, D.; Iglesias, M.; Orrillo, M.; Abalo, A.; Rodríguez, C.; Brozos, E.; et al. Plasma ctDNA RAS mutation analysis for the diagnosis and treatment monitoring of metastatic colorectal cancer patients. Ann. Oncol. 2017, 28, 1325-1332. [CrossRef] [PubMed]

36. Grasselli, J.; Elez, E.; Caratù, G.; Matito, J.; Santos, C.; Macarulla, T.; Vidal, J.; Garcia, M.; Viéitez, J.; Paéz, D.; et al. Concordance of blood- and tumor-based detection of RAS mutations to guide anti-EGFR therapy in metastatic colorectal cancer. Ann. Oncol. 2017, 28, 1294-1301. [CrossRef] [PubMed]

37. Normanno, N.; Cervantes, A.; Ciardiello, F.; De Luca, A.; Pinto, C. The liquid biopsy in the management of colorectal cancer patients: Current applications and future scenarios. Cancer Treat. Rev. 2018, 70, 1-8. [CrossRef]

38. Siravegna, G.; Mussolin, B.; Venesio, T.; Marsoni, S.; Seoane, J.; Dive, C.; Papadopoulos, N.; Kopetz, S.; Corcoran, R.; Siu, L.; et al. How liquid biopsies can change clinical practice in oncology. Ann. Oncol. 2019, 30, 1580-1590. [CrossRef] 
39. Hutchinson, L.; Kirk, R. High drug attrition rates-Where are we going wrong? Nat. Rev. Clin. Oncol. 2011, 8, 189-190. [CrossRef]

40. Barretina, J.; Caponigro, G.; Stransky, N.; Venkatesan, K.; Margolin, A.A.; Kim, S.; Wilson, C.J.; Lehar, J.; Kryukov, G.V.; Sonkin, D.; et al. The Cancer Cell Line Encyclopedia Enables Predictive Modelling of Anticancer Drug Sensitivity. Nature 2012, 483, 603-607. [CrossRef]

41. Medico, E.; Russo, M.; Picco, G.; Cancelliere, C.; Valtorta, E.; Corti, G.; Buscarino, M.; Isella, C.; Lamba, S.; Martinoglio, B.; et al. The molecular landscape of colorectal cancer cell lines unveils clinically actionable kinase targets. Nat. Commun. 2015, 6, 7002. [CrossRef]

42. Marisa, L.; De Reynies, A.; Duval, A.; Selves, J.; Gaub, M.P.; Vescovo, L.; Etienne-Grimaldi, M.-C.; Schiappa, R.; Guenot, D.; Ayadi, M.; et al. Gene Expression Classification of Colon Cancer into Molecular Subtypes: Characterization, Validation, and Prognostic Value. PLoS Med. 2013, 10, e1001453. [CrossRef] [PubMed]

43. Lazzari, L.; Corti, G.; Picco, G.; Isella, C.; Montone, M.; Arcella, P.; Durinikova, E.; Zanella, E.R.; Novara, L.; Barbosa, F.; et al. Patient-Derived Xenografts and Matched Cell Lines Identify Pharmacogenomic Vulnerabilities in Colorectal Cancer. Clin. Cancer Res. 2019, 25, 6243-6259. [CrossRef] [PubMed]

44. Sartore-Bianchi, A.; Trusolino, L.; Martino, C.; Bencardino, K.; Lonardi, S.; Bergamo, F.; Zagonel, V.; Leone, F.; Depetris, I.; Martinelli, E.; et al. Dual-targeted therapy with trastuzumab and lapatinib in treatment-refractory, KRAS codon 12/13 wild-type, HER2-positive metastatic colorectal cancer (HERACLES): A proof-of-concept, multicentre, open-label, phase 2 trial. Lancet Oncol. 2016, 17, 738-746. [CrossRef]

45. Riedl, A.; Schlederer, M.; Pudelko, K.; Stadler, M.; Walter, S.; Unterleuthner, D.; Unger, C.; Kramer, N.; Hengstschläger, M.; Kenner, L.; et al. Comparison of cancer cells in 2D vs 3D culture reveals differences in AKT-mTOR-S6K signaling and drug responses. J. Cell Sci. 2016, 130, 203-218. [CrossRef]

46. Schumacher, D.; Andrieux, G.; Boehnke, K.; Keil, M.; Silvestri, A.; Silvestrov, M.; Keilholz, U.; Haybaeck, J.; Erdmann, G.; Sachse, C.; et al. Heterogeneous pathway activation and drug response modelled in colorectal-tumor-derived 3D cultures. PLoS Genet. 2019, 15, e1008076. [CrossRef]

47. Schutte, M.; Risch, T.; Abdavi-Azar, N.; Boehnke, K.; Schumacher, D.; Keil, M.; Yildiriman, R.; Jandrasits, C.; Borodina, T.; Amstislavskiy, V.; et al. Molecular Dissection of Colorectal Cancer in Pre-Clinical Models Identifies Biomarkers Predicting Sensitivity to Egfr Inhibitors. Nat. Commun. 2017, 8, 14262. [CrossRef]

48. Hollandsworth, H.M.; Amirfakhri, S.; Filemoni, F.; Schmitt, V.; Wennemuth, G.; Schmidt, A.; Hoffman, R.M.; Singer, B.B.; Bouvet, M. Anti-carcinoembryonic antigen-related cell adhesion molecule antibody for fluorescence visualization of primary colon cancer and metastases in patient-derived orthotopic xenograft mouse models. Oncotarget 2020, 11, 429-439. [CrossRef]

49. Yoon, S.N.; Park, J.H.; Lwin, T.M.; Miyake, K.; Singh, S.R.; Hoffman, R.M.; Bouvet, M. Tumor-sealing Surgical Orthotopic Implantation of Human Colon Cancer in Nude Mice Induces Clinically-relevant Metastases Without Early Peritoneal Carcinomatosis. Anticancer. Res. 2019, 39, 4065-4071. [CrossRef]

50. Kawaguchi, K.; Murakami, T.; Suetsugu, A.; Kiyuna, T.; Igarashi, K.; Hiroshima, Y.; Zhao, M.; Zhang, Y.; Bouvet, M.; Clary, B.; et al. High-efficacy targeting of colon-cancer liver metastasis with Salmonella typhimurium A1-R via intra-portal-vein injection in orthotopic nude-mouse models. Oncotarget 2016, 8, 19065-19073. [CrossRef]

51. Fumagalli, A.; Drost, J.; Suijkerbuijk, S.J.E.; Van Boxtel, R.; De Ligt, J.; Offerhaus, G.J.; Begthel, H.; Beerling, E.; Tan, E.H.; Sansom, O.J.; et al. Genetic dissection of colorectal cancer progression by orthotopic transplantation of engineered cancer organoids. Proc. Natl. Acad. Sci. USA 2017, 114, E2357-E2364. [CrossRef] [PubMed]

52. Fumagalli, A.; Suijkerbuijk, S.J.E.; Begthel, H.; Beerling, E.; Oost, K.C.; Snippert, H.J.; Van Rheenen, J.; Drost, J. A surgical orthotopic organoid transplantation approach in mice to visualize and study colorectal cancer progression. Nat. Protoc. 2018, 13, 235-247. [CrossRef] [PubMed]

53. O’Rourke, K.P.; Loizou, E.; Livshits, G.; Schatoff, E.M.; Baslan, T.; Manchado, E.; Simon, J.; Romesser, P.B.; Leach, B.; Han, T.; et al. Transplantation of engineered organoids enables rapid generation of metastatic mouse models of colorectal cancer. Nat. Biotechnol. 2017, 35, 577-582. [CrossRef] [PubMed]

54. Vlachogiannis, G.; Hedayat, S.; Vatsiou, A.; Jamin, Y.; Fernández-Mateos, J.; Khan, K.; Lampis, A.; Eason, K.; Huntingford, I.; Burke, R.; et al. Patient-derived organoids model treatment response of metastatic gastrointestinal cancers. Science 2018, 359, 920-926. [CrossRef]

55. Kondo, J.; Inoue, M. Application of Cancer Organoid Model for Drug Screening and Personalized Therapy. Cells 2019, 8, 470. [CrossRef] 
56. Balasubramanian, S.; Hurley, L.H.; Neidle, S. Targeting G-quadruplexes in gene promoters: A novel anticancer strategy? Nat. Rev. Drug Discov. 2011, 10, 261-275. [CrossRef]

57. Neidle, S. Quadruplex Nucleic Acids as Novel Therapeutic Targets. J. Med. Chem. 2016, 59, 5987-6011. [CrossRef]

58. Lavrado, J.; Brito, H.; Borralho, P.; Ohnmacht, S.A.; Kim, N.-S.; Leitão, C.; Pisco, S.; Gunaratnam, M.; Rodrigues, C.M.P.; Moreira, R.; et al. KRAS oncogene repression in colon cancer cell lines by G-quadruplex binding indolo[3,2-c]quinolines. Sci. Rep. 2015, 5, 9696. [CrossRef]

59. Biroccio, A.; Porru, M.; Rizzo, A.; Salvati, E.; D’Angelo, C.; Orlandi, A.; Passeri, D.; Franceschin, M.; Stevens, M.F.; Gilson, E.; et al. DNA Damage Persistence as Determinant of Tumor Sensitivity to the Combination of Topo I Inhibitors and Telomere-Targeting Agents. Clin. Cancer Res. 2011, 17, 2227-2236. [CrossRef]

60. Porru, M.; Zizza, P.; Franceschin, M.; Leonetti, C.; Biroccio, A. EMICORON: A multi-targeting G4 ligand with a promising preclinical profile. Biochim. Biophys. Acta Gen. Subj. 2017, 1861, 1362-1370. [CrossRef]

61. Porru, M.; Artuso, S.; Salvati, E.; Bianco, A.; Franceschin, M.; Diodoro, M.G.; Passeri, D.; Orlandi, A.; Savorani, F.; D’Incalci, M.; et al. Targeting G-Quadruplex DNA Structures by EMICORON Has a Strong Antitumor Efficacy against Advanced Models of Human Colon Cancer. Mol. Cancer Ther. 2015, 14, 2541-2551. [CrossRef] [PubMed]

62. Pompili, L.; Porru, M.; Caruso, C.; Biroccio, A.; Leonetti, C. Patient-derived xenografts: A relevant preclinical model for drug development. J. Exp. Clin. Cancer Res. 2016, 35, 189. [CrossRef] [PubMed]

63. Mohamed, A.J.; Yu, L.; Bäckesjö, C.-M.; Vargas, L.; Faryal, R.; Aints, A.; Christensson, B.; Berglof, A.; Vihinen, M.; Nore, B.F.; et al. Bruton's tyrosine kinase (Btk): Function, regulation, and transformation with special emphasis on the PH domain. Immunol. Rev. 2009, 228, 58-73. [CrossRef] [PubMed]

64. Novero, A.; Ravella, P.M.; Chen, Y.; Dous, G.; Liu, D. Ibrutinib for B cell malignancies. Exp. Hematol. Oncol. 2014, 3, 4. [CrossRef] [PubMed]

65. Younes, A.; Sehn, L.H.; Johnson, P.; Zinzani, P.L.; Hong, X.; Zhu, J.; Patti, C.; Belada, D.; Samoilova, O.; Suh, C.; et al. Randomized Phase Iii Trial of Ibrutinib and Rituximab Plus Cyclophosphamide, Doxorubicin, Vincristine, and Prednisone in Non-Germinal Center B-Cell Diffuse Large B-Cell Lymphoma. J. Clin. Oncol. 2019, 37, 1285-1295. [CrossRef]

66. Molina-Cerrillo, J.; Alonso-Gordoa, T.; Gajate, P.; Grande, E. Bruton's tyrosine kinase (BTK) as a promising target in solid tumors. Cancer Treat. Rev. 2017, 58, 41-50. [CrossRef]

67. Grassilli, E.; Pisano, F.; Cialdella, A.; Bonomo, S.; Missaglia, C.; Cerrito, M.G.; Masiero, L.; Ianzano, L.; Giordano, F.; Cicirelli, V.; et al. A novel oncogenic BTK isoform is overexpressed in colon cancers and required for RAS-mediated transformation. Oncogene 2016, 35, 4368-4378. [CrossRef] [PubMed]

68. Lavitrano, M.; Ianzano, L.; Bonomo, S.; Cialdella, A.; Cerrito, M.G.; Pisano, F.; Missaglia, C.; Giovannoni, R.; Romano, G.; McLean, C.M.; et al. BTK inhibitors synergise with 5-FU to treat drug-resistant TP53-null colon cancers. J. Pathol. 2019, 250, 134-147. [CrossRef]

69. Michie, K.; Bermeister, A.; Robertson, N.O.; Goodchild, S.C.; Curmi, P.M.G. Two Sides of the Coin: Ezrin/Radixin/Moesin and Merlin Control Membrane Structure and Contact Inhibition. Int. J. Mol. Sci. 2019, 20, 1996. [CrossRef]

70. Leiphrakpam, P.D.; Rajput, A.; Mathiesen, M.; Agarwal, E.; Lazenby, A.J.; Are, C.; Brattain, M.G.; Chowdhury, S. Ezrin expression and cell survival regulation in colorectal cancer. Cell. Signal. 2014, 26, 868-879. [CrossRef]

71. Mori, K.; Toiyama, Y.; Otake, K.; Ide, S.; Imaoka, H.; Okigami, M.; Okugawa, Y.; Fujikawa, H.; Saigusa, S.; Hiro, J.; et al. Successful identification of a predictive biomarker for lymph node metastasis in colorectal cancer using a proteomic approach. Oncotarget 2017, 8, 106935-106947. [CrossRef]

72. Anastas, J.N.; Moon, R.T. Wnt Signalling Pathways as Therapeutic Targets in Cancer. Nat. Rev. Cancer 2013, 13, 11-26. [CrossRef] [PubMed]

73. McDonald, S.L.; Silver, A. The opposing roles of Wnt-5a in cancer. Br. J. Cancer 2009, 101, 209-214. [CrossRef] [PubMed]

74. Weeraratna, A.T.; Jiang, Y.; Hostetter, G.; Rosenblatt, K.; Duray, P.; Bittner, M.; Trent, J.M. Wnt5a signaling directly affects cell motility and invasion of metastatic melanoma. Cancer Cell 2002, 1, 279-288. [CrossRef]

75. Mikels, A.J.; Nusse, R. Purified Wnt5a protein activates or inhibits beta-catenin-TCF signaling depending on receptor context. PLoS Biol. 2006, 4, e115. [CrossRef] [PubMed] 
76. Bakker, E.R.; Das, A.M.; Helvensteijn, W.; Franken, P.F.; Swagemakers, S.; Van Der Valk, M.A.; Hagen, T.T.; Kuipers, E.J.; Van Veelen, W.; Smits, R. Wnt5a promotes human colon cancer cell migration and invasion but does not augment intestinal tumorigenesis in Apc 1638N mice. Carcinogenesis 2013, 34, 2629-2638. [CrossRef]

77. Bergenfelz, C.; Medrek, C.; Ekström, E.; Jirström, K.; Janols, H.; Wullt, M.; Bredberg, A.; Leandersson, K. Wnt5a Induces a Tolerogenic Phenotype of Macrophages in Sepsis and Breast Cancer Patients. J. Immunol. 2012, 188, 5448-5458. [CrossRef]

78. Mehmeti, M.; Bergenfelz, C.; Kallberg, E.; Millrud, C.R.; Bjork, P.; Ivars, F.; Johansson-Lindbom, B.; Kjellstrom, S.; Andre, I.; Leandersson, K. Wnt5a Is a Tlr2/4-Ligand That Induces Tolerance in Human Myeloid Cells. Commun. Biol. 2019, 2, 176. [CrossRef]

79. Kelly, M.G.; Alvero, A.; Chen, R.; Silasi, D.-A.; Abrahams, V.M.; Chan, S.; Visintin, I.; Rutherford, T.; Mor, G. TLR-4 Signaling Promotes Tumor Growth and Paclitaxel Chemoresistance in Ovarian Cancer. Cancer Res. 2006, 66, 3859-3868. [CrossRef]

80. Nicolussi, A.; D’Inzeo, S.; Capalbo, C.; Giannini, G.; Coppa, A. The role of peroxiredoxins in cancer. Mol. Clin. Oncol. 2017, 6, 139-153. [CrossRef]

81. Lipinski, S.; Pfeuffer, S.; Arnold, P.; Treitz, C.; Aden, K.; Ebsen, H.; Falk-Paulsen, M.; Gisch, N.; Fazio, A.; Kuiper, J.; et al. Prdx4 limits caspase- 1 activation and restricts inflammasome-mediated signaling by extracellular vesicles. EMBO J. 2019, 38, e101266. [CrossRef] [PubMed]

82. Yi, N.; Xiao, M.B.; Ni, W.K.; Jiang, F.; Lu, C.H.; Ni, R.-Z. High expression of peroxiredoxin 4 affects the survival time of colorectal cancer patients, but is not an independent unfavorable prognostic factor. Mol. Clin. Oncol. 2014, 2, 767-772. [CrossRef]

83. Zhu, D.-J.; Chen, X.-W.; Wang, J.-Z.; Ju, Y.-L.; Yang, M.-Z.O.; Zhang, W.-J. Proteomic analysis identifies proteins associated with curcumin-enhancing efficacy of irinotecan-induced apoptosis of colorectal cancer LOVO cell. Int. J. Clin. Exp. Pathol. 2013, 7, 1-15.

84. Shi, H.; Hayes, M.; Kirana, C.; Miller, R.J.; Keating, J.P.; Stubbs, R.S. Overexpression of aminoacylase 1 is associated with colorectal cancer progression. Hum. Pathol. 2013, 44, 1089-1097. [CrossRef] [PubMed]

85. Wei, X.; Li, J.; Xie, H.; Ling, Q.; Wang, J.; Lu, D.; Zhou, L.; Xu, X.; Zheng, S. Proteomics-based identification of the tumor suppressor role of aminoacylase 1 in hepatocellular carcinoma. Cancer Lett. 2014, 351, 117-125. [CrossRef] [PubMed]

86. Yu, B.; Liu, X.; Cao, X.; Zhang, M.; Chang, H. Study of the expression and function of ACY1 in patients with colorectal cancer. Oncol. Lett. 2017, 13, 2459-2464. [CrossRef] [PubMed] 